\title{
The role of perceptions about trade and inequality in the backlash against globalization
}

\section{Barbara Dluhosch $^{1}$ (D)}

Received: 25 February 2021 / Accepted: 27 October 2021 / Published online: 22 November 2021

(c) The Author(s) 2021

\begin{abstract}
Many countries in the Western hemisphere are experiencing a political backlash against globalization. When explaining this phenomenon, much of the extant research draws on the distributional effects of international competition, in particular the opposition to trade by those who are adversely affected. Using cross-sectional data on subjective well-being from the World Values Survey and the European Values Study and combing these self-reports with trade and incomes data, this paper contributes to this strand of research by focusing on the subjective element in the formation of anti-trade sentiments. It thus explores how the role of international trade in the income distribution is being perceived at the individual level. Simulations based on the data reveal that matters of income inequality are evaluated differently, depending on how deeply the respective economy is integrated into world markets: results suggest that the extent of trade globalization amplifies any negative effect of income inequality on subjective well-being. If the role of international openness in the income distribution is perceived to be more pronounced than it actually is, the subjective element has wider politico-economic implications; it carries the risk of costly anti-trade policies without necessarily narrowing the income distribution.
\end{abstract}

Keywords Perceptions · Income distribution · International trade · Protectionism · Globalization

\section{Introduction}

Over the last decade, protectionism has gained popularity. While US trade policy has been very much in the focus (e.g. World Trade Organization 2019; Bown and Kolb 2021), other countries have made intensive use of restrictive trade measures

Barbara Dluhosch

international.econ@hsu-hh.de

1 Department of Business and Economics, Helmut Schmidt University, Holstenhofweg 85, 22043 Hamburg, Germany 
as well, as, for instance, it has been documented for the G20 by Evenett and Fritz (2021: 51-127) in the Global Trade Alert.

Much of research relates the demand for protectionist policies to adverse labor market and income effects. Notwithstanding the relevance of actual income effects because of trade in the discontent with globalization, this paper takes a different approach, which to the best of our knowledge, has received limited attention so far. It brings in the subjective element in the interpretation of data on trade globalization and inequality as another channel possibly fueling anti-trade sentiments. Drawing on subjective well-being reports provided by the 2017-2020 World Values Survey and the European Values Study, the paper explores whether matters of income inequality are perceived differently depending on the degree of trade globalization. Combining the self-reports on subjective well-being with data on trade globalization and income inequality in simulation studies, it is found that globalization has a negative leverage effect on how inequality affects subjective well-being. Seemingly, the data on inequality are interpreted differently: matters of income inequality are considered in particular an issue when individuals think of them as being related to trade globalization. Results thus suggest that perceptions about the role of globalization in income inequality may thus be an additional factor at work in anti-trade sentiments explaining the widespread support which international trade restrictions received lately.

\section{Literature review}

The relationship between trade globalization and inequality has been the object of extensive discussion and study. Although not undisputed as to its magnitude, a great many studies see the spread of anti-globalization sentiments as an outcome of income effects and insecurities triggered by international trade (see, for instance contributions by Pavcnik (2011), Nguyen (2017), Rodrik (2018), Hoekman and Nelson (2018), Wood (2018), Bajo-Rubio and Yan (2019) and Walter (2021)). By creating winners and losers, international trade is seen as widening the income inequality within the trading economies, thus triggering a discontent with openness by those negatively affected. The number of studies on voting behavior, which present evidence in support of adverse income effects and job losses of trade is, in fact, considerable (see, for instance, Che et al. (2016), Jensen et al. (2017) and Autor et al. (2020) for the US; Guiso et al. (2017) and Colantone and Stanig (2018a) for Europe; Dippel et al. (2015) and Putzhammer (2018) for Germany; Caselli et al. (2020) for Italy and Colantone and Stanig (2018b) for the UK). Other studies focus more closely on preferences over trade policy (see, inter alia, Scheve and Slaughter (2001), Mayda and Rodrik (2005) and Hanson et al. (2007), and the surveys by the Pew Research Center (2014) or Bluth (2016)). Nevertheless, they too refer to actual income effects of trade globalization.

While explaining much of the demand for protection, they are difficult to reconcile with the fact that low-skill intensive production in low-skill abundant countries often also receives protection, although, according to traditional trade theoretic reasoning, the low(er)-skilled should experience income gains in these economies. Lü 
et al. (2012) offer inequity aversion as an explanation to this oddity. This effect may also operate, alas, it remains to be explained why distributional issues are evaluated differently depending on trade with the bias apparently present across the whole income spectrum. ${ }^{1}$ Research by Mayda and Rodrik (2005) suggests that other socioeconomic aspects, such as nation-centered questions about feeling locally attached or about being proud of the Home countries' social and political institutions or economic achievements may also be important in explaining the variation in attitudes over trade (similarly Mansfield and Mutz (2013)). Inglehart and Norris (2016), in analyzing European Social Survey data on the support for populist parties, find evidence that it is much more cultural values across a wide range of social groups rather than just the low-skilled low-income groups in skill abundant economies forming the backbone of the backlash against globalization. Research based on US panel data by Mutz (2018) adds to the evidence of perceived status threat by previously dominant groups as main drivers in political attitudes (as opposed to the more narrow economic losses of the low-skilled). Likewise, by focusing on support for trade policies, Fattore and Fitzpatrick (2016) find empirical evidence for Latin America that it is not only objective measures, but also perceptions with reference to income distributions which matter. ${ }^{2}$ All of these findings suggest that looking at issues of (subjective) well-being (rather than exclusively on trade and income inequality data) might deliver additional information as to possible explanations of this widespread a backlash.

A number of studies try to add insights along these lines. Looking at (mental) health issues, Pierce and Schott (2020) find evidence that post-2000 U.S.-China trade liberalization went in tandem with an increase in suicide deaths in U.S. counties and by workers specialized in manufacturing. Results are in line with empirical studies for the U.S. by Case and Deaton (2015), and Graham and Pinto (2019), who find evidence that the various societal strata show much heterogeneity as to sociopsychological indicators, such as all-cause deaths and perceptions of stress, insecurity, and, in particular, hope and confidence in the future. Accordingly, poorer rural whites in their middle ages are the least optimistic about their personal outlook. The socio-geographic pattern suggests again a relationship to shifts in the demand for labor because of trade as it was presumably these strata, which were affected the most by import competition from abroad. On a similar account, Colantone et al. (2019) present indication for the UK that competition and the associated adjustment costs cause mental stress. In addition, Hummels et al. (2016) find adverse health effects of exports in Danish matched worker-firm data.

\footnotetext{
${ }^{1}$ Research by Hainmueller and Hiscox (2006) and Feigenbaum and Hall (2015) casts additional doubts on the linkage as any such link presupposes an understanding of distributional consequences of trade for which empirical evidence seems to be weak. See also Garrett et al. (2016) and Flynn et al. (2017), both of which explore (mis-)perceptions in the formation of preferences over policies. Combined with propagation mechanisms inherent to social media, (mis-)perceptions may give rise to what Leitner et al. (2021) identify as "infodemics".

2 This relates to studies showing that perceptions about fairness in the income generation process and the resulting income distribution do have an impact on subjective well-being (Bjørnskov et al. 2013) and on preferences over trade policies (Rodrik 2018).
} 
However, Bjørnskov et al. (2008), by focusing on life satisfaction as revealed in self-reports, find that openness of a country is among the small number of variables that robustly affect individual life satisfaction in a positive way. Dluhosch and Horgos (2013) show that there are various facets of (trade) globalization, which are perceived very differently, some positive, some negative. Moreover, Khun et al. (2015) find that, on an overall account, trade restrictions correlate with lower, rather than higher levels of (self-reported) well-being. However, none of these studies explore whether changes in the income distribution are perceived differently conditional on the level of globalization.

Whether and how matters of income distribution per se affect subjective wellbeing has been at the center of a number of studies, with most of them finding a depressing effect (e.g. Alesina et al. (2004) and Graham and Felton (2006), but with results also partly inconclusive (e.g. Hopkins (2008), Rözer and Kraaykamp (2013), Dluhosch et al. (2014) and García-Muñoz et al. (2019); see also Schneider (2016) for an overview or the meta-study by Ngamaba et al. (2018)). ${ }^{3}$ Nonetheless, and most importantly from our perspective, these studies do not account for globalization nor for any interaction effects of income inequality and globalization in subjective wellbeing. Schalembier (2016) identifies measures of comparative performance vis-à-vis other countries to become more important for subjective well-being as international exposure increases. He thus explores interaction effects between income inequality and globalization (or international exposure for that matter), but considering crossnational comparisons rather than within-country income distributions.

This paper shares some of those perspectives in that the backlash might be rooted in a much broader sentiment, which shows up in data on (self reports of) subjective well-being. It goes a step forward though by looking at whether subjective wellbeing data reveals that an increase in income inequality is in particular depressing subjective well-being when accompanied by a deepening of trade globalization. To gain insights into how income inequality is linked to subjective well-being conditional on how the economy is exposed to international competition, the paper employs an ordered logistic regression which regresses measures of income inequality and trade globalization on subjective well-being. The analysis on the conditional effects is then carried out for different levels of globalization supposing individuals were exposed to the same (measure of) income inequality.

Simulation studies on the data including the subjective dimension suggest that, even though the starting level is the same, marginal changes in income inequality tend to depress subjective well-being more strongly the more open the country. Income inequality is thus particularly considered an issue in open economies, although not necessarily being a result thereof. Such varying perceptions on how domestic and international competition affect well-being might be another avenue

\footnotetext{
${ }_{3}^{3}$ Research on the nexus between inequality and subjective well-being has a long tradition. The aforementioned studies focus primarily on macro-micro-mediated effects (as does this paper). However, it is worth mentioning that there is also a large body of primarily micro-oriented research exploring for instance peer-group effects. On this, see, for instance, Luttmer (2005), Tsoukis (2007), Clark et al. (2008) or Van Praag (2011) to name a few.
} 
leading to a resistance to trade globalization - and a reflection of an "Us vs. Them" mindset on matters of competition. ${ }^{4}$

The paper proceeds along the following lines. "Variables and data" and "Stylized facts from 27 countries" provide information on the variables and the data, and deliver some stylized facts on subjective well-being, international openness and income distributions. "Empirical strategy" then discusses the appropriate empirical strategy for exploiting the variance in subjective well-being as a proxy for how the relationship between trade globalization and income inequality is being perceived and evaluated at the individual level. "Regression analysis" and "Simulation studies on the leverage effect of globalization" present the results of the regression analysis and various simulation studies, respectively. Finally, "Robustness checks on simulation results" checks for the robustness, and "Conclusions" concludes.

\section{Variables and data}

To explore whether income inequality has a more depressing effect on subjective well-being when individuals attribute inequality to globalization, we combine micro- and macro-data at the individual and the national level from different sources. Data availability and consistency require to adopt a cross-sectional perspective with 2017-2020 data. Table 1 and the Online Appendix provide an overview of the data and (access to) the sources.

As to the micro-data, we draw on the World Values Survey (WVS) and the European Values Study (EVS). The 2021 Spring edition of the joint data set (based on waves 7 and 5, respectively) contains self reports on subjective well-being of 127,358 individuals in 79 countries ( 45 from the WVS, 34 from the EVS), as well as opinions on various matters and characteristics of these individuals. Interviews in the 79 countries took place at slightly different points in time between 2017 and 2020. They are nevertheless cross-sectional data from the same survey round. The dataset holds information about two dimensions of subjective well-being, satisfaction with life and happiness. Following the classification by Diener (1984), satisfaction with life refers to the cognitive dimension of subjective well-being (in contrast to the emotional feelings, and thus transitory, happiness). Therefore, it is the relevant variable for this study. The data are in ordered categorical format (i.e. on a Cantril ladder), ranging from 1 ("dissatisfied") to 10 ("satisfied"). The distribution across ordered categories 1-10 thus constitutes the natural output variable for our analysis.

While the focus of this study is on individual perceptions of how the macro situation influences life (in particular with respect to how inequality and globalization affects well-being), previous research has shown that in any case individual circumstances matter for subjective well-being (e.g., Scheve and Slaughter (2001)

\footnotetext{
4 On notions of "Us vs. Them" see Allport (1954) and Bremmer (2018), and the evidence in Mutz and Kim (2017) on "in-group favoritism". The role of perceptions as to trade and income inequality also tie in with experimental studies by Feng et al. (2021) according to which foreign, and especially Chinese, investment in the US is considered different than domestic investment.
} 

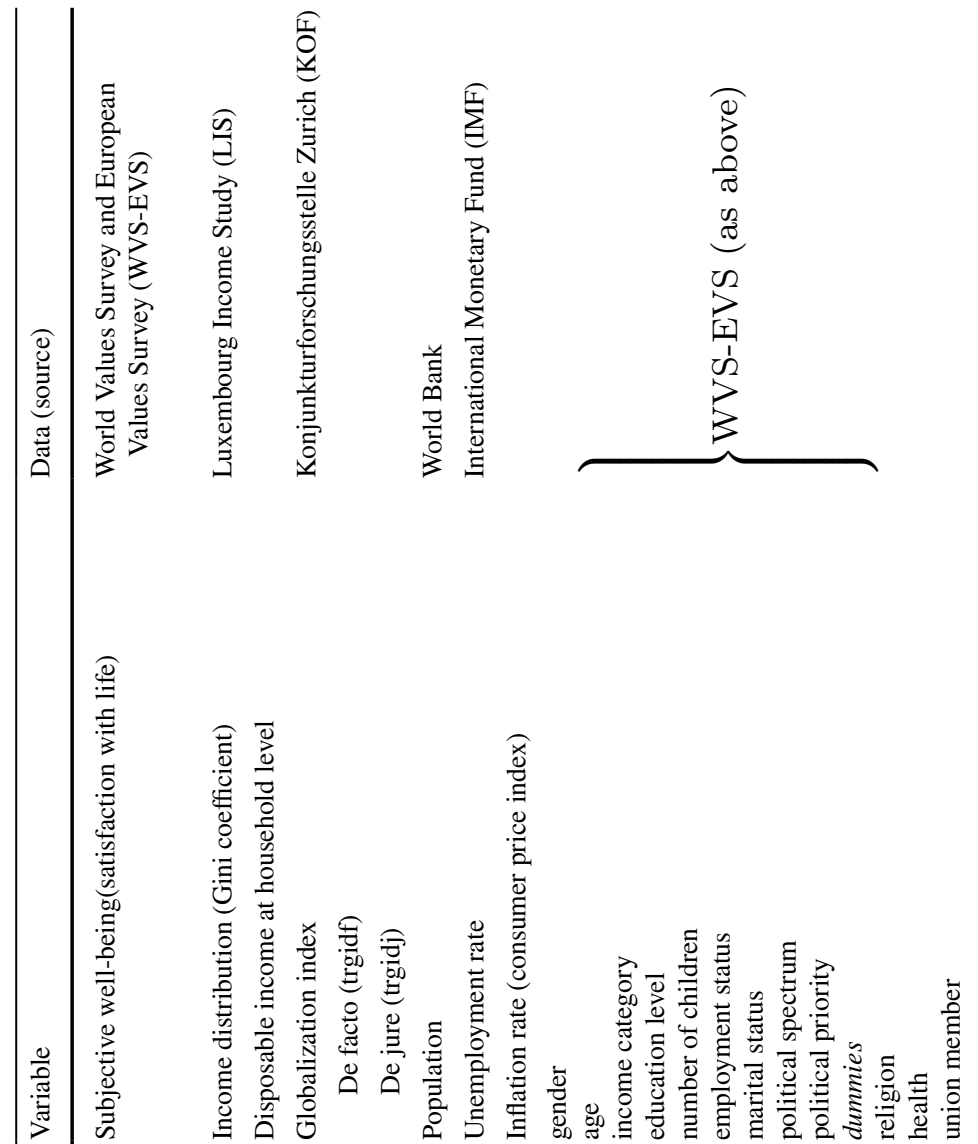
and Bjørnskov et al. (2008)). We will account for these findings by controlling for individual characteristics such as age, gender, level of education, number of children, marital status, employment status, union membership, health, where individuals locate themselves in the political and the income spectrum, whether religion is important to them and whether they rank growth more important than the environment. All of the data are from the 2017-2020 joint WVS-EVS dataset. In some instances, however, we will slightly regroup and recode the raw data so as to better cater to our focus.

With regard to the macro-data, we first obtain information about income inequality in the form of the Gini coefficient from the Luxembourg Income Study (LIS) 2021 , which is by far the most consistent dataset of disposable (monetary and nonmonetary) income at the household level. ${ }^{5}$ Data referring to the situation around 2017 (wave X, 2021 Spring edition) cover 37 countries, and it also includes the corresponding market incomes. Although income inequality is the main regressor in the analysis, it is the interaction with the extent of globalization as individually perceived, which is of particular interest. Globalization scores prepared by the Konjunkturforschungsstelle Zurich (KOF) can be regarded as appropriate, as highlighted by many studies on the impacts of globalization. ${ }^{6}$ In trying to capture the various dimensions of globalization (economic, social, political), the KOF publishes a number of subindices, including the de facto trade globalization indicator (trgidf), which is the most closely related to sentiments about inequality and globalization. It amalgamates information on exports and imports of goods and services, and-by means of the Herfindahl-Hirschman index-also accounts for trade partner diversity. Research by Dluhosch and Horgos (2013), though, has established that, in order to obtain robust and proper information on the exposure to trade globalization, one has to control for trade policies. Otherwise, trade indicators in regressions pick up two different issues, namely what individuals see because of trade volumes, for instance, when buying goods and services and what the business environment is with respect to trade. Trade policies constitute more of an option value of trade: e.g., goods may be freely tradable according to policies, but trade volumes may nevertheless be low. The distinction already shows up in many countries scoring very differently in both dimensions. Accommodating the need to control for trade policies, the KOF publishes an index of de jure trade globalization (trgidj) by blending data on trade regulations, tariffs and trade agreements which we will thus use as a control. In addition, we will control for population size, unemployment rates and (consumer) price inflation with IMF data. In particular, unemployment and inflation have been shown by way of a "misery index" to affect subjective well-being substantially in previous research (e.g. Di Tella et al. (2001) and Dluhosch et al. (2014)).

\footnotetext{
${ }^{5}$ Alternative inequality indices, such as the Atkinson index, give particular weight to the lower parts of the income distribution. Effects turn out to be slightly less pronounced, but nevertheless similar to the Gini.

${ }^{6}$ See Gygli et al. (2019) on the current edition of the index, Dreher (2006) on previous editions, and, Potrafke (2015) on the many uses.
} 

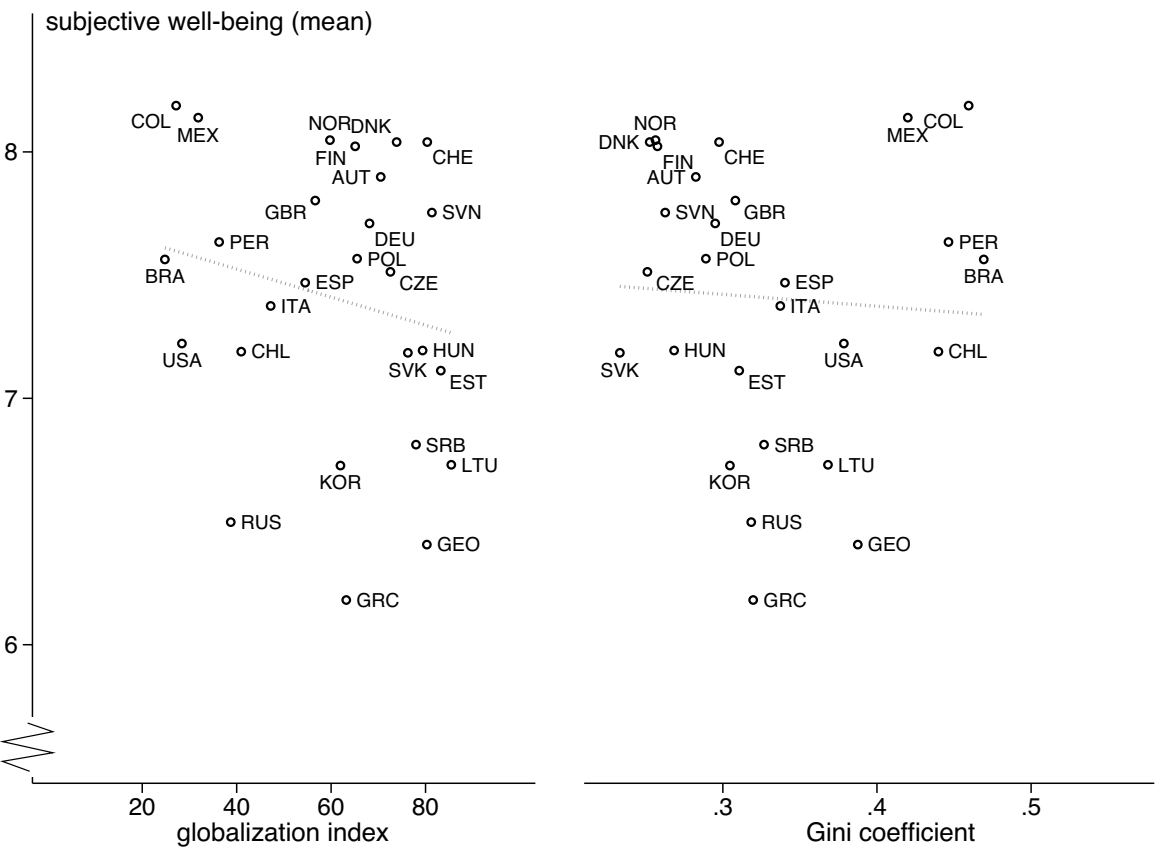

Fig. 1 (Raw) data on trade globalization, income inequality and subjective well-being

Other macro-variables are likely to affect life satisfaction. Potential candidates discussed in the literature are, e.g., political freedom, civil rights, governance issues, political stability, quality of government and bureaucracy, social trust and many other aspects that form the fabric of society. Even sunshine has been identified to have some impact on well-being (think of suicide rates in some Scandinavian countries during the comparatively long dark spell of Winter). Diener et al. (2013), or Helliwell and Wang (2011), to mention just two studies, discuss some of the these circumstances, thus giving a taste of the many aspects which might be relevant in one way or another. However, many of these dimensions are somewhat linked to standards of living or globalization, others are, by all standards, sufficiently uncorrelated, thus not confounding results (see, for instance, Jordahl (2009) or Berggren and Nilsson (2015)). Merging the relevant data yields a set of 48,683 individuals in 27 countries with overlapping information on all of the variables of interest.

\section{Stylized facts from 27 countries}

This section provides some stylized facts based on the data described in "Variables and data". Figure 1 displays cross-country information on the association between subjective well-being and the extent of globalization on the one hand, and subjective well-being and income inequality on the other hand. The left panel of Fig. 1 plots the mean of self-reported well-being of individuals in each of the 27 countries 
against the globalization index (trgidf), the right panel against the Gini coefficient (based on disposable household income).

The left panel may suggest a negative nexus between subjective well-being and (trade) globalization. The downward slope caters to the notion that, on average, trade globalization depresses subjective well-being, however, with the effect weak as data points are fairly spread out. The right panel, though, with income inequality as measured by the Gini coefficient, shows hardly any correlation at all with subjective well-being. The raw data thus seem at least inconclusive as to how income inequality per se relates to subjective well-being. This seems to be in line with the heterogeneity in the results reported by the extant literature (see the survey by Ngamaba et al. (2018)), and with some studies even suggesting a (slightly) positive relationship (e.g. Starmans et al. (2017) and García-Muñoz et al. (2019)).

While the two panels in Fig. 1 provide a first glimpse on the main variables of interest, they come with two important caveats: firstly, in the diagram, subjective well-being refers to averages. Averages, however, do not account for the variance at the micro level nor do they account for the fact that the underlying data are in ordinal categorical format (and with the number of categories limited, i.e. with a lower and an upper bound) for which aggregation into a single number is not trivial. A thorough analysis should fully exploit all the information in the data, including any variance at the individual level. This is particularly important since perceptions are formed at the individual level and may differ even for individuals being exposed to the same macro data. Considering the properties of the data and our research question thus requires to dig more deeply into the actual shape of the individual data and to focus on various sub-groups. We will deal with this difficulty by analyzing the impacts of openness and income inequality for each score of subjective well-being separately. Otherwise, positive and negative impacts are implicitly amalgamated, thereby masking the information which is of utmost interest to us. Combined with extensive simulation studies, the disaggregated perspective with respect to scores will deliver insights on the moderating effect of globalization on the well-being effects of inequality. The second caveat refers to the issue of covariates confounding the effect of the two variables on subjective well-being. In the present context, this is not just an omitted variables issue. The bounded nature of the output scale (subjective well-being) implies that predictions of the impact of changes in the two variables on the distribution of well-being scores is not independent of the values of these and all other covariates. The next section will outline the methods that properly account for these issues.

The shape of the data on globalization and income distribution in itself is already thought-provoking. Figure 2 seems to challenge the widespread belief that it is simply negative income effects of trade that fuels the backlash against globalization: the right panel in Fig. 2 suggests that countries which are more open to international competition as measured by the KOF index actually are more homogeneous with respect to disposable household incomes. Clearly, income cleavages may have many dimensions (with respect to skills, occupations, regions, age groups, gender etc.), which need not show up in the aggregate. The overall Gini may nevertheless provide information on the homogeneity of a society. In trying to reconcile the data with the traditional understanding, one 

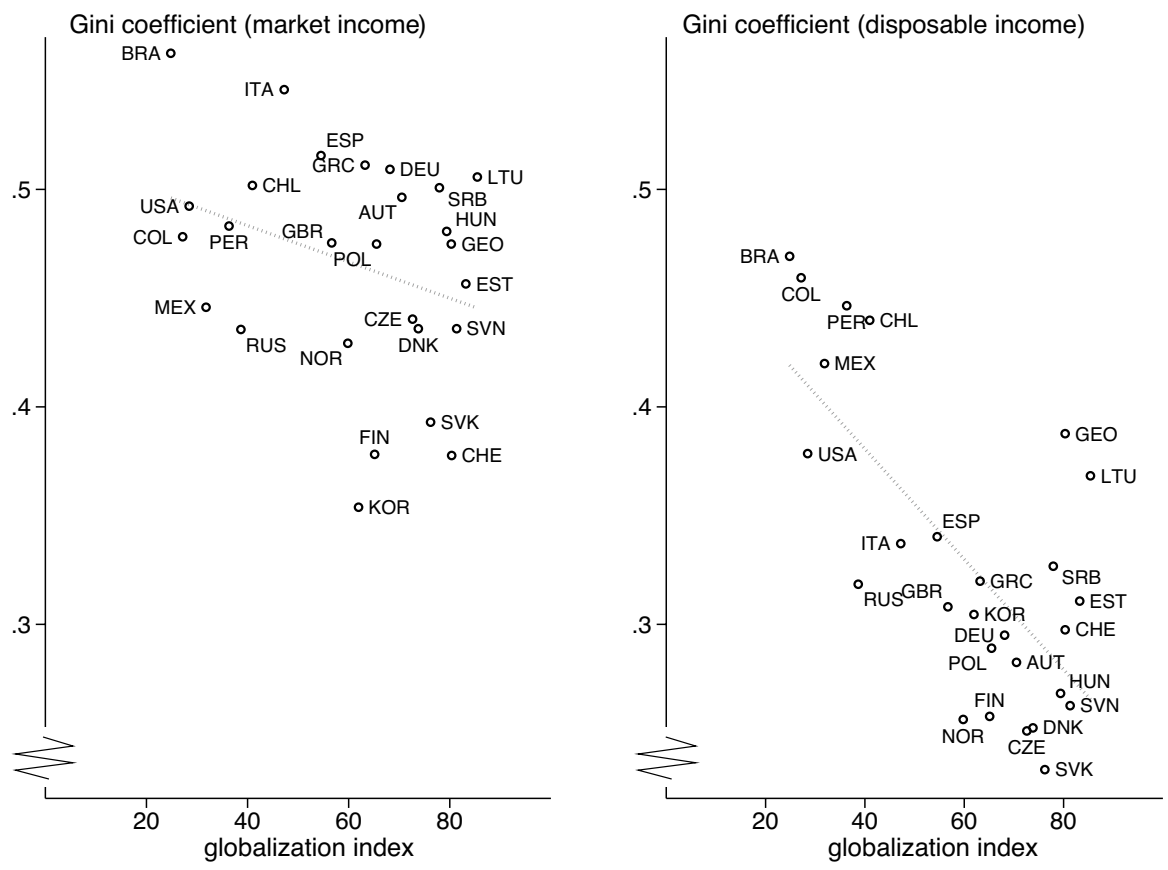

Fig. 2 (Raw) data on trade globalization and inequality: market vs. disposable income

might argue that the negative correlation between globalization and the Gini of disposable income results from social policies cushioning income effects of globalization by means of redistribution. Gozgor and Ranjan (2017) actually find evidence for redistribution increasing in tandem with globalization. The underlying argument is that openness is more likely to be socially accepted and embraced if income effects are mitigated by social policies (in particular income policies), thus shielding individuals effectively from income risks associated with trade. This argument has been prominently advanced by Rodrik (1998), and it has been propagated by the concept of "embedded liberalism" in its various shadings (see Lewis (2018) for a discussion including trade). Interestingly, though, the correlation between the Gini coefficient and the globalization index is in any case negative, no matter whether the Gini coefficient is based on market or on disposable (household) incomes (left versus right panel of Fig. 2). The negative correlation is compatible though with ex ante, that is, before trade, more homogeneous countries allowing for a higher degree of exposure to international competition. The interpretation of the macro situation at the individual level may then explain why nevertheless there is a backlash against globalization, even in comparatively homogeneous countries in terms of income distributions.

A closer examination of the individual data, which keeps these insights and caveats in mind, shows that there is indeed more in the data than what a first eyeball test reveals. Explicitly addressing these issues with appropriate methods, which account for the ordinal character of the individual information and the non-linearity because 
of the bounded nature of the output variable, delivers that macro variables are rated quite differently at the individual level, depending on their actual combination.

\section{Empirical strategy}

Factoring in the nature of the output variable "subjective well-being" calls for an ordered logistic regression model. This type of model can deal with both issues, namely that data are in categorical format and that probabilities as well as marginal effects of the regressors cannot be constant across all levels of well-being with the well-being domain being bounded. Because of the limited range, changes in probabilities tend to be lower at both ends of the well-being spectrum than those in the middle of the spectrum.

Within this type of model, we employ an interaction variable approach, which allows to assess how the degree of globalization affects the link between subjective well-being and income inequality. We thus estimate the following ordered logistic regression model

$$
\begin{aligned}
S_{i j}^{*}= & \beta_{0}+\beta_{1} \text { gini }_{j}+\beta_{2} \operatorname{trgidf}_{j}+\beta_{3}\left(\text { gini }_{j} \times \operatorname{trgidf}_{j}\right) \\
& +\beta_{4} \operatorname{trgidj}_{j}+\beta_{5} \operatorname{pop}_{j}+\beta_{6} u \_ \text {rate } \\
& +\beta_{7} \mathrm{cpi}_{j}+\gamma X_{i j}+\epsilon_{i j}
\end{aligned}
$$

where $S_{i j}^{*}$ is the latent (unobserved) variable containing information on (subjective) well-being of individual $i$ in country $j$. However, while the latent variable can assume any value on a real scale, the observed data are in categorical format. Estimating cut-off rates $\alpha$, which divide the values of the latent variable into groups, then maps the latent results into categories 1 to 10 on the Cantril ladder of subjective well-being with $S_{i j}=1$ for $S_{i j}^{*} \leq \alpha_{1}, S_{i j}=2$ for $\alpha_{1}<S_{i j}^{*} \leq \alpha_{2}$ etc. etc., and, finally, $S_{i j}=10$ for $S_{i j}^{*}>\alpha_{9}$. This procedure yields the probability of a particular score of subjective well-being and thus also the distribution across scores.

With regard to the independent variables, gini ${ }_{j}$ refers to the within-country distribution of disposable household incomes of country $j$, trgidf ${ }_{j}$ to de facto globalization, $\left(\right.$ gini $_{j} \times$ trgidf $\left._{j}\right)$ to the interaction effect on subjective well-being, $\operatorname{trgidj}_{j}$ to de jure globalization, $\operatorname{pop}_{j}$ to the size of the population, $u \_$rate ${ }_{j}$ to the unemployment rate, $\mathrm{cpi}_{j}$ to the inflation rate of (consumer) prices, and matrix $X_{i j}$ to individual controls relating to socio-demographic characteristics of individuals as listed in Table 1. Because the regression combines aggregate with individual variables, the error term, $\epsilon_{i j}$, is clustered at the country level. To achieve robust standard errors, we apply the Huber/White sandwich estimator.

\section{Regression analysis}

Table 2 presents the results of the ordered logit regression. The estimated $\beta$ coefficients apparently show how each of the covariates in the model affects well-being. Many of the variables have the expected sign as suggested by previous research. This applies in particular 
Table 2 Perceptions of globalization and income inequality: regression results

\begin{tabular}{lll}
\hline Variables & Coef. & S.E. \\
\hline
\end{tabular}

Dependent variable: subjective well-being (satisfaction with life)

Key regressors

$\begin{array}{lll}\text { Globalization (de facto: trgidf) } & 0.898 * * * & (0.253) \\ \text { Income distribution (Gini) } & 0.160 * * * & (0.0331) \\ \text { Globalization (de facto) x distribution } & -0.0269 * * * & (0.00673) \\ \text { Controls } & & \\ \text { Globalization (de jure: trgidj) } & 0.158 * & (0.0852) \\ \text { Population (ln) } & -0.0373 & (0.0798) \\ \text { Unemployment rate } & -0.0406 * * & (0.0188) \\ \text { Inflation rate (cpi) } & 0.0568 & (0.0642) \\ \text { Age } & 0.0119 * & (0.0256) \\ \text { Age2 } & 0.0515 * * * & (0.00741) \\ \text { Male } & -0.105 * * * & (0.0267)\end{array}$

Income categories

(Reference: income category 5)

$\begin{array}{lll}\text { inc1 } & -0.352 * * * & (0.108) \\ \text { inc2 } & -0.185^{* * *} & (0.0700) \\ \text { inc3 } & -0.122^{*} & (0.0646) \\ \text { inc4 } & -0.0940^{* *} & (0.0397) \\ \text { inc6 } & 0.0876^{*} & (0.0501) \\ \text { inc7 } & 0.230^{* * *} & (0.0531) \\ \text { inc8 } & 0.389 * * * & (0.0707) \\ \text { inc9 } & 0.415 * * * & (0.0860) \\ \text { inc10 } & 0.545^{* * *} & (0.0953) \\ \text { No answer } & 0.149 * & (0.0855)\end{array}$

Level of education

(Reference: upper secondary)

$\begin{array}{lll}\text { No edu } & -0.0186 & (0.209) \\ \text { Primary } & 0.254^{*} & (0.148) \\ \text { Lower secondary } & 0.0577 & (0.0602) \\ \text { Post secondary } & -0.0268 & (0.0713) \\ \text { Short tertiary } & 0.0810 & (0.0715) \\ \text { Bachelor equiv. } & 0.0282 & (0.0483) \\ \text { Master equiv } & 0.0036 & (0.0629) \\ \text { Doc } & 0.120 & (0.137) \\ \text { Other } & 0.0134 & (0.162)\end{array}$

Number of children

(Reference: 2 children)

\begin{tabular}{lll} 
No children & $-0.0866 * *$ & $(0.0344)$ \\
1 child & $-0.0688 * * *$ & $(0.0265)$ \\
$\geq 3$ children & $0.128 * * *$ & $(0.0332)$ \\
\hline
\end{tabular}


Table 2 (continued)

\begin{tabular}{lll}
\hline Variables & Coef. & S.E. \\
\hline Marital status & & \\
(Reference: married and partner) & & \\
$\quad$ Sep., div., wid. & $-0.404^{* * *}$ & $(0.0441)$ \\
Single & $-0.242^{* * *}$ & $(0.0436)$ \\
Political spectrum & & \\
(Reference: center) & & \\
Left & 0.0047 & $(0.0242)$ \\
Right & $0.196^{* * *}$ & $(0.0465)$ \\
No answer & 0.0537 & $(0.0550)$ \\
Priority to & & \\
(Reference: environment) & & \\
Rather growth & $-0.128^{* * *}$ & $(0.0296)$ \\
Other & $-0.164^{* * *}$ & $(0.0451)$ \\
No answer & $-0.146^{* * *}$ & $(0.0523)$ \\
Other (dummy variables) & & \\
Unemployed & $-0.274^{* * *}$ & $(0.0791)$ \\
Union member & $0.154^{* * *}$ & $(00.0524)$ \\
Not religious & $-0.154^{* * *}$ & $(0.0445)$ \\
Not good health & $-1.111^{* * *}$ & $(0.0730)$ \\
Observations & 48,683 & \\
Clusters & 27 & \\
Pseudo R-squared & 0.0453 & \\
Clustered errors & YES & \\
\hline
\end{tabular}

Robust standard errors (S.E.) in parentheses

$* * * p<0.01, * * p<0.05, * \mathrm{p}<0.1$

to individual characteristics: lower income strata (based on one's own perception), bad health, being single, divorced or widowed, or being male all have a depressing effect on subjective well-being. As to macro circumstances, the unemployment rate turns up significant and negative. De jure globalization, by contrast, seems to be appreciated, reflecting a positive option value of trade. Most interesting from our perspective is that the combined effect of income inequality and trade globalization comes out negative and significant.

However, although seemingly informative, the interpretation of regression results with ordered categorical data is not straight forward. Even though it is tempting to infer marginal effects from the individual coefficients in Table 2, one has to keep in mind that doing so implicitly assumes that coefficients are linear, despite of them being in fact non-linear. Coefficients are non-linear because the outcome domain (subjective well-being) is bounded from above $(\leq 10)$ and below $(\geq 1) .{ }^{7}$ One way to

\footnotetext{
${ }^{7}$ See, for instance, Norton et al. (2004), Buis (2010) and Williams (2012) for an extensive discussion of the technical details, and Karaca-Mandic et al. (2012), VanderWeele and Knol (2014) or Norton and Dowd (2018) of applications, mostly in medical research. Shying away from these challenges, socio-economic studies therefore often sacrifice the proper ordered logit model in favor of an OLS estimation as if preference orderings were numerically measureable (e.g. Hessami 2010; Bjørnskov et al. 2013). The
} 


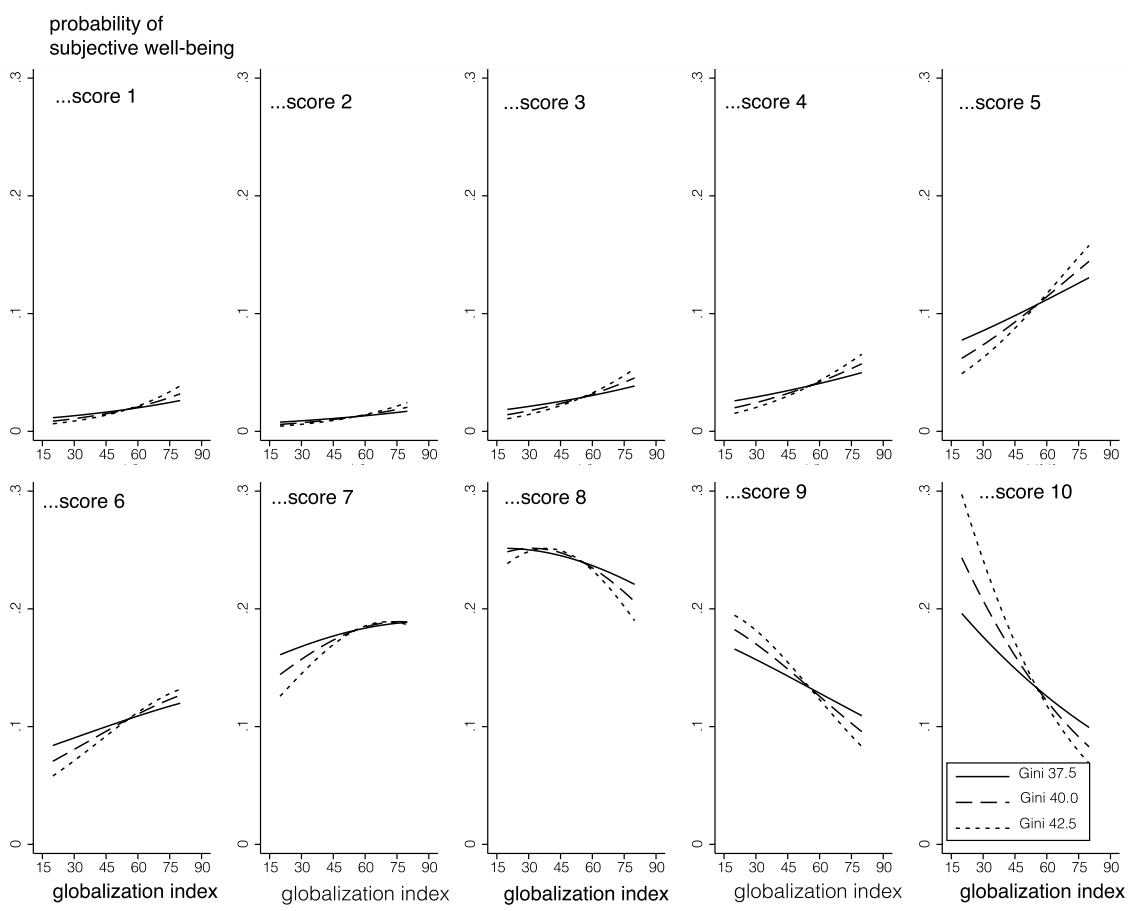

Fig. 3 Adjusted predictions for subjective well-being scores 1- 10 at various degrees of globalization and income inequality

deal with this fact is to hold all controls either at their mean values or as observed and to estimate the probability of a particular well-being score at various (representative) values of the variable of interest, that is, as if all individuals were exposed to the same value of the variable of interest. For small changes in the variable, the difference in probabilities can then be interpreted as the marginal effect. They are, though, adjusted marginal effects. They are derived for particular values of key variables. As such, they vary with (for instance) the exposure (to trade). Notably, results from this procedure differ from those listed in Table 2.

\section{Simulation studies on the leverage effect of globalization}

Simulation exercises, which track probabilities at various levels of the key variables, provide insights on how globalization modifies the effects of inequality on subjective well-being. Figure 3 displays results of the first simulation, which

Footnote 7 (continued)

linear approximation might be considered as technically justifiable in case of a large number of ordinally ranked scores. However, Fig. 4 demonstrates that marginal effects are anything but constant, as assumed in OLS. Hence, the caveat. 
tracks probabilities of well-being scores 1 to 10 , supposing all individuals were about to face the same degree of globalization, and a particular income inequality as measured by the Gini. Probabilities are calculated by assuming that the Gini coefficient takes on values 37.5, 40 and 42.5, and, (2) de facto globalization, as measured by the KOF-index, were in any case 10, 20, 30, and up to 90, or any value in between, rather than the value actually observed. The variation in the Gini coefficient covers the upper part in the actual distribution of the Ginis; the globalization index spans the whole domain in the dataset. All other variables listed in Table 1 are assumed to enter preferences as observed.

Two results stand out: (1) for lower scores of well-being, probabilities increase in openness while for higher scores they decrease. This holds for all of the three Gini coefficients in the simulation exercise; (2) for each score of subjective wellbeing considered separately, there is a pivotal value of the KOF-index. For all KOF-values above, probabilities for well-being scores at the upper end of the spectrum are lower the higher the Gini coefficients. The negative differential effect of a higher Gini coefficient on predicted probabilities even increases in the globalization index. For all KOF-values below, the reverse holds true.

The first result is consistent with the notion that, on average, de facto globalization is anything but welcomed: individuals tend to self-report lower well-being at higher degrees of globalization. The second result lends support to the belief that any negative attitude towards inequality is more pronounced the more globalized the economy - at least for individuals living in countries comparatively deeply integrated into world markets.

The impacts on the probability distribution of subjective well-being scores are anything but minor. Consider the example of a Gini coefficient of 40, displayed by the dashed curve in Fig. 3. To avoid possible specifics as to the tails of the wellbeing domain, one may focus on changes in the self-reporting to well-being scores 3 and 9. To give an example, if the globalization index increases, say, from 40 to 50 , predicted probabilities increase from 2.1 to 2.5 for a score of 3 . They decrease, though, from 15.6 to 14.4 for a score of 9 . The discontent continues to hold at higher levels of globalization: for each step of an increase in the index, for instance, by 5 units, predicted probabilities of score 3 increase by approx. $8 \%$, until almost $5 \%$ of the individuals report a score of 3 at the upper end of the globalization spectrum. Predicted probabilities of score 9 decrease between 7.4 and $4.3 \%$ at each step, until having almost declined to 60 percent of their initial level. Comparing effects of trade globalization at different levels of the Gini shows that at higher levels of globalization the depressing effect of inequality on well-being is accentuated by globalization: consider the largest fraction of individuals in the sample, namely those reporting a score of 8: at a Gini of 37.5, the probability of a score of 8 is 1 percent lower as the globalization index climbs from 60 to 65 , at a Gini of 40 it is 2 percent lower and at a Gini of 42.5 it is even 3 percent lower.

Adjusted marginal effects of variations in the Gini coefficient (from its observed value) at various levels of globalization further substantiate these findings: Fig. 4 summarizes the effects of a one-percentage point increase in the Gini-coefficient on predicted probabilities for all scores 1 (bottommost) to 10 (topmost) at different values of the globalization index, and including the usual confidence interval. 

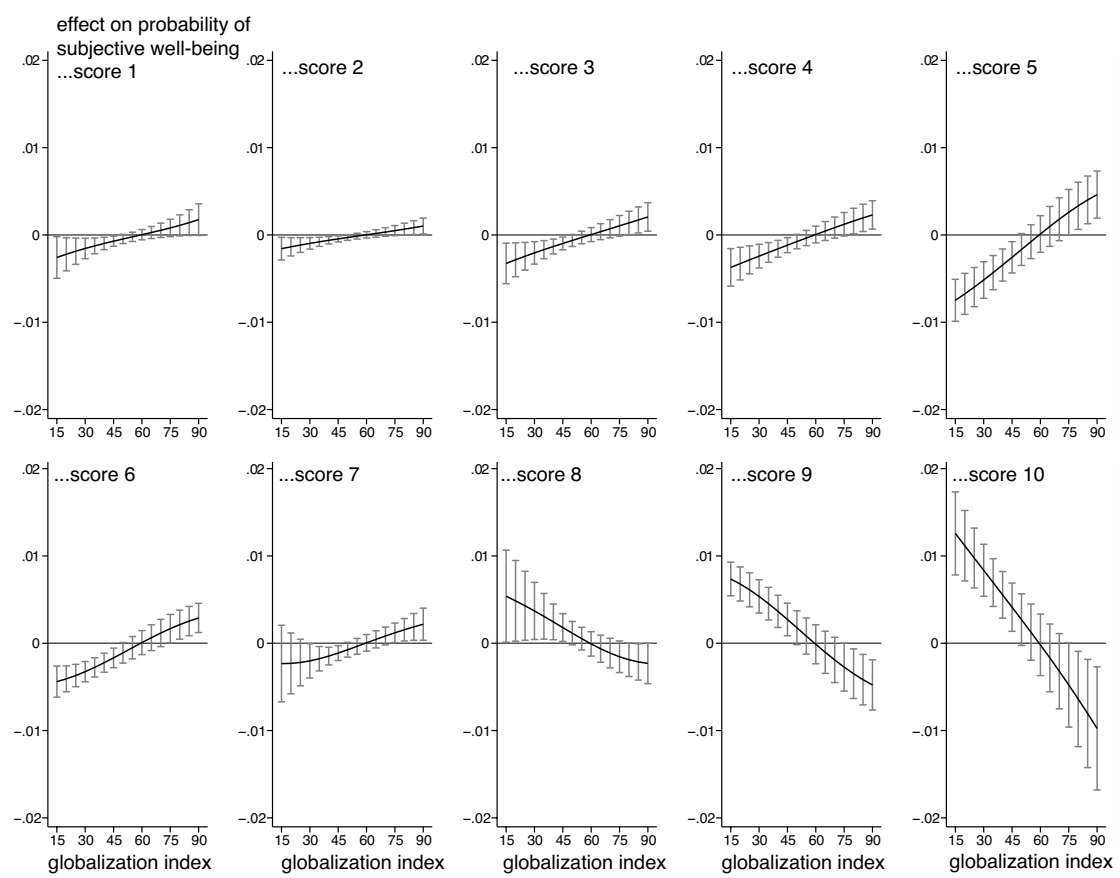

Fig. 4 Marginal effects of an increase in the Gini (based on disposable household income) from its observed value on the predicted probability of a particular well-being score, at various degrees of globalization

Positive results signal an increase in the probability of reporting the respective wellbeing score. Negative results indicate the opposite. According to the leftmost panel in the top row of Fig. 4, individuals thus become more satisfied with their lives even if the Gini coefficient increases by one percentage point, provided that openness is still low. At higher levels of openness, they become increasingly less satisfied with life. While there is a substantial amount of fuzziness in the data at such a low wellbeing score because of the small number of individuals in this group, effects become sharper at the upper, much more densely populated, scores.

Regarding the topmost scores of well-being, which are displayed to the right of the bottom row, results show that, at high(er) degrees of globalization, the marginal effect is negative and significantly so. Moreover, depressing effects become larger as globalization deepens. Hence, marginal effects of income inequality on well-being differ, depending on the degree of globalization. Openness thus seems to change how matters of income distribution are being seen. Rather than toward inequality per se, the discontent may be directed toward openness with competition from abroad serving as a scapegoat, thus giving rise to a backlash against globalization, and to protectionist policies. 

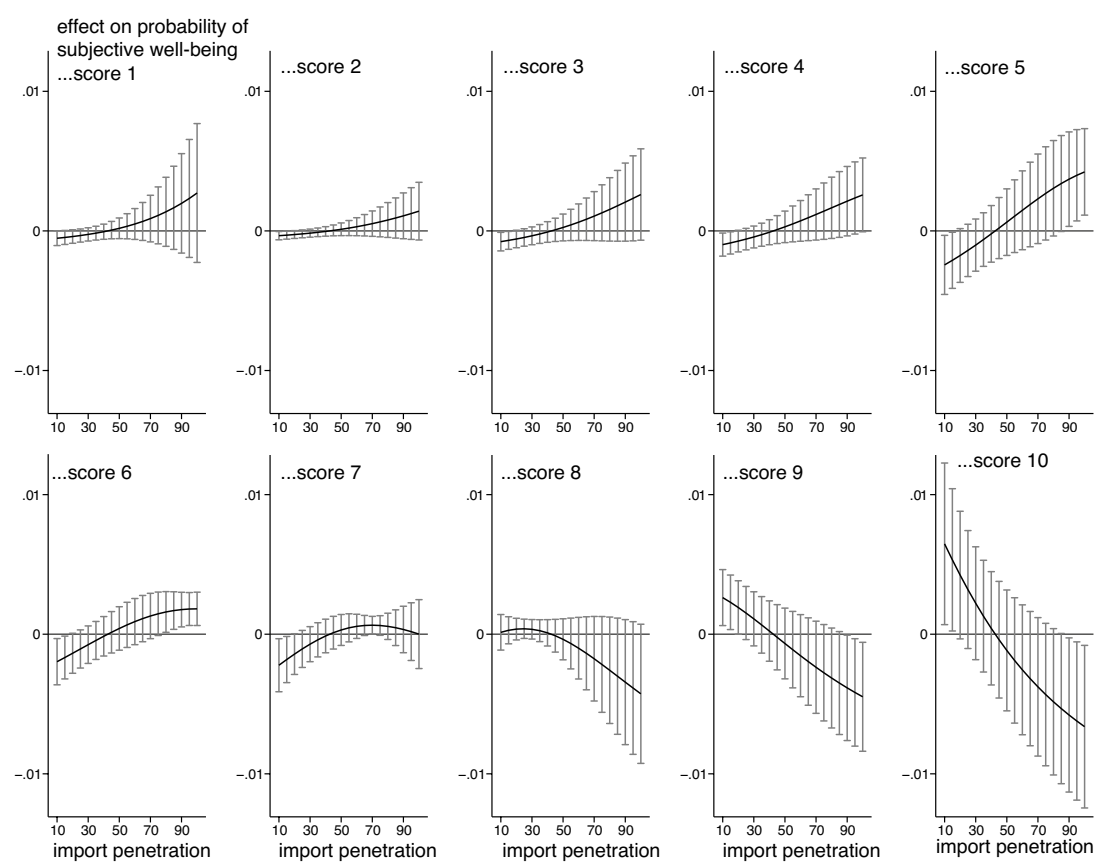

Fig. 5 Marginal effects of an increase in the Gini (based on disposable household income) on the predicted probability of a particular well-being score, at various degrees of import penetration

\section{Robustness checks on simulation results}

Results are robust with respect to alternative measures of a country's openness. Specifically, indices of import penetration, that is, the ratio of imports to domestic demand (GDP minus exports plus imports), might be considered an alternative to the KOF indices of globalization used in the previous Section(s). They are published regularly by the World Bank in their set of indicators describing the state of the world economy (see Table 1 and Lindner (2005) on the methodology). Although being a more narrow concept compared to the KOF indices, import penetration ratios focus more closely on import competition. The link to perceptions about globalization may thus be even stronger than in case of the KOF indices on trade globalization. The de jure globalization index by the KOF may then be substituted by corresponding trade freedom data of the Heritage Foundation (see Table A1, Online Appendix) while the rest of the data from Table 1 remain the same.

Figure 5 displays the results of marginal effects on predicted probabilities, again disaggregated according to scores of well-being. Predictions are a bit less sharp. However, the interaction comes out in very much the same way as with the KOFindices: a marginal increase in the observed Gini coefficient exhibits an (increasingly) negative leverage effect on subjective well-being - when being accompanied with a higher import penetration (provided imports have surpassed a pivotal value in domestic demand). 
Work by Gozgor (2021) suggests that globalization affects trust in government. Therefore, another (possible) transmission channel worth considering might be that via trust in government (and its policies) subjective well-being affects macro variables, including trade exposure and income inequality. However, there is no indication of any such reverse effect in our data. The 2017-2020 WVS-EVS dataset provides information on trust in government (as ordered data with categories from "none at all" to "a great deal"). The polychoric correlation of the data with subjective well-being of the approx. 50,000 individuals in the 27 countries, that is, the procedure of calculation, which takes account of the fact that both of the variables are measured on an ordinal scale, is but fairly low though (0.11). Moreover, all of the results prove to be robust with respect to the sign and significance of coefficients, even when segmenting the data according to the level of trustworthiness of government.

Results also turn out to be robust with respect to different specifications of the model. Instead of clustering at the country level, one may consider an explicit multilevel approach by estimating the following model $S_{i j}^{*}=\beta_{0}+\beta_{1}^{\prime} X_{i j}+\beta_{2}^{\prime} Z_{j}+\beta_{3}\left(\right.$ gini $\left._{j} \times \operatorname{trgidf}_{j}\right)+u_{j}+\varepsilon_{i j}^{*}$, with subscripts $i$ and $j$ denoting the individual and the country, respectively. ${ }^{8} u_{j}$ is the random intercept at the country level, which now explicitly accounts for the impact of unobserved variables on subjective well-being at the country level, whereas $\varepsilon_{i j}^{*}$ is the within-country individual level disturbance term. $X_{i j}$ contains the set of controls at the micro (that is, the individual) level; $Z_{j}$ holds the macro (that is, the country) level variables, and the term $\left(\right.$ gini $_{j} \times \operatorname{trgidf}_{j}$ ) is supposed to capture again any interaction effect of the main variables of interest.

In this specification, vectors $\beta_{1}^{\prime}, \beta_{2}^{\prime}$ are the coefficients (in the form of fixed effects), which are to be estimated; $\beta_{3}$ denotes the coefficient of the interaction term and $\beta_{0}$ the coefficient in the null model, that is, disregarding all other variables. Figure 6 summarizes the (adjusted) marginal effects of an increase in the Gini coefficient at various levels of the globalization index, however, now estimated by means of a multi-level ordered logistic regression. The structure of the data (number of countries vs. number of individuals and variables) might be considered an issue and thus to weaken results. As can be seen, main results nevertheless stand up to this variation in the model specification. ${ }^{9}$

Summing up, there is robust empirical evidence that a widening of the income distribution is in particular considered an issue if it is perceived as being related to globalization and competition from abroad.

\footnotetext{
${ }^{8}$ On dealing with macro- and micro-data by means of a multi-level, cross-country, analysis with reference to subjective well-being, see, e.g., Schyns (2002), Schalembier (2016) or García-Muñoz et al. (2019).

9 Another (alternative) method that might suggest itself is a partial least squares (PLS) approach as introduced into statistical modeling by Wold (1982). The PLS approach tries to identify interaction effects of variables by means of latent components being extracted from the predictor variables while also factoring in the structure of the outcome variable. The latent components, however, are derived from linear combinations of the variables while the relationship is actually non-linear. On the crucial issues, which come with the weights, see, e.g. Rönkkö et al. (2016).
} 

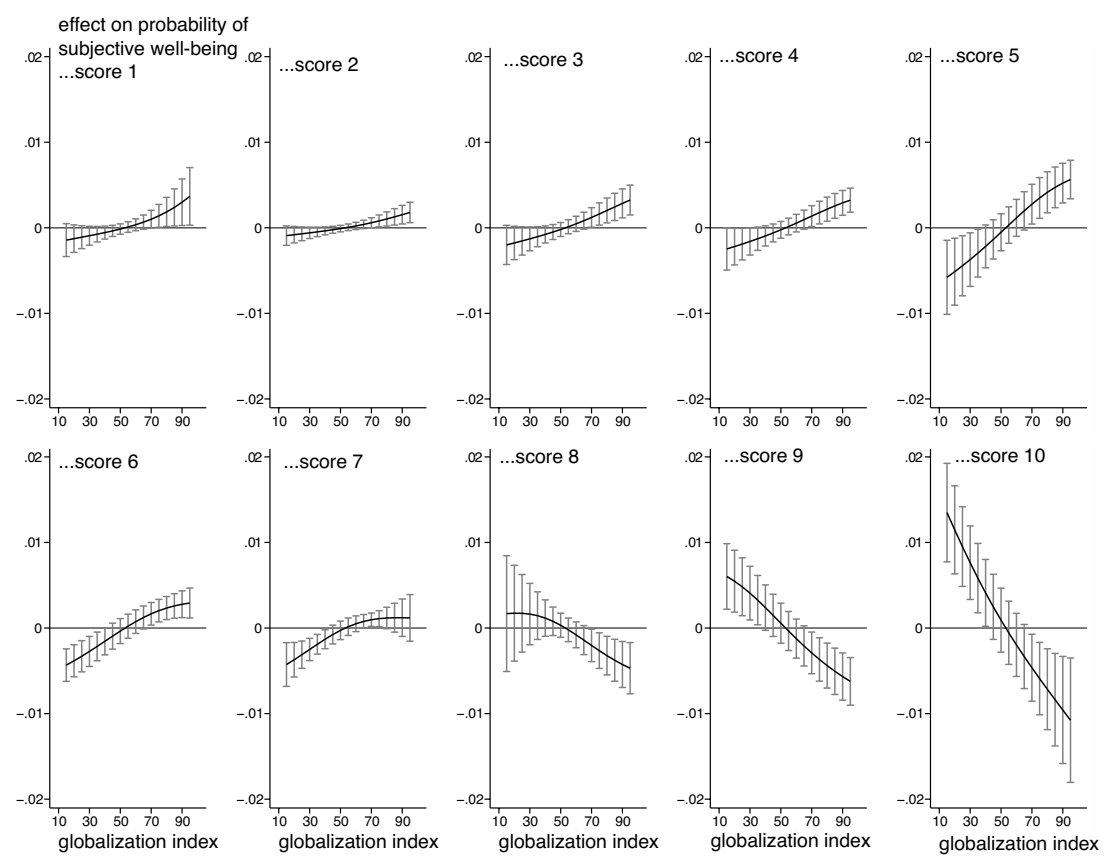

Fig. 6 Marginal effects of an increase in the Gini (based on disposable household income) from its observed value on the predicted probability of a particular well-being score, at various degrees of globalization (multilevel specification)

\section{Conclusion}

The backlash against globalization, and international trade in particular, is usually seen as an outcome of the distributional impact of trade. While generally associated with welfare gains, not all stand to benefit from trade. Rather, foreign competition drives some industries out of business, with specialized labor and capital losing out. This winner-loser perspective has some truth to it, as, for instance, research on the correlation of regionally concentrated declining industries and (regional) voting behavior has shown.

However, the fact that anti-trade sentiments have gained political support across quite broad a range of countries and sectors is a bit difficult to explain by only referring to the losers in a more globalized economy. Rather, the seemingly widespread approval of protectionist measures suggests that there is another element which adds momentum to the anti-trade climate. In trying to explain this momentum, the paper focuses on the subjective element in interpreting developments in trade globalization and income inequality as another channel of discontent besides the actual winner-loser divide. Using 2017-2020 WVS-EVS data on subjective well-being of approx. 50,000 individuals and 27 countries, it finds that trade globalization unfolds a depressing effect on how income inequality is being perceived to affect well-being. Extensive simulation studies based on an ordered 
logit model of subjective well-being suggest that the same level and change in income inequality is evaluated differently depending on how deeply the respective economy is integrated into world markets via trade: a one-percentage point increase in the observed income inequality as measured by the Gini coefficient tends to lower self-reported scores of subjective well-being, with the adverse effect accentuated at higher degrees of globalization as measured by various indicators. Accordingly, globalization has a negative leverage on perceptions about inequality as measured by the Gini. The subjective element in the interpretation of inequality data suggests that there is also a scapegoat argument at work, namely that competition from abroad is held responsible for domestic developments as to the income distribution. If marginal changes in the income distribution (notably, from the same level of inequality) are ascribed to globalization, perceptions may give rise to populist policies and costly protectionism, however, without necessarily narrowing the income distribution. Obviously, this does not imply that there are no distributional effects of globalization or to negate that anti-globalization sentiments and protectionist tendencies might be fueled by losers opposing international competition. Rather, these perceptions are to be seen as an additional channel via which protectionism might gain support.

The analysis lends itself to a number of extensions. One research question worth exploring may be whether this sentiment is being driven by feelings about a loss in political sovereignty and a shift in governance from the national to the inter- or supranational level, which is disapproved by the citizens. At higher levels of globalization local issues of income distribution may be considered more difficult to address with local policies, no matter whether they are due to globalization or other factors.

Supplementary Information The online version contains supplementary material available at https://doi. org/10.1007/s43546-021-00171-5.

Acknowledgements Previous versions of this paper were presented at Conferences of the International Society for Quality-of-Life Studies (ISQOLS), the Western Political Science Association (WPSA), the International Studies Association (ISA), and the Western Economic Association International (WEAI). Comments by conference participants were very helpful and are gratefully acknowledged. In particular, I would like to thank Michael Allen, Brad LeVeck, Craig N. Murphy, and Evren Ors for many valuable comments and suggestions.

Funding Open Access funding enabled and organized by Projekt DEAL. No funding has been received for preparing this study.

Availability of data and material All data used in this study are publicly available (in case of LIS: for researchers of supporting institutions). See the Appendix for data sources.

\section{Declarations}

Conflict of Interest The author declares that she has no conflict of interest.

Ethical approval This article does not contain any studies with human participants or animals preformed by the author. 
Open Access This article is licensed under a Creative Commons Attribution 4.0 International License, which permits use, sharing, adaptation, distribution and reproduction in any medium or format, as long as you give appropriate credit to the original author(s) and the source, provide a link to the Creative Commons licence, and indicate if changes were made. The images or other third party material in this article are included in the article's Creative Commons licence, unless indicated otherwise in a credit line to the material. If material is not included in the article's Creative Commons licence and your intended use is not permitted by statutory regulation or exceeds the permitted use, you will need to obtain permission directly from the copyright holder. To view a copy of this licence, visit http://creativecommons.org/licen ses/by/4.0/.

\section{References}

Alesina A, Di Tella R, MacCulloch R (2004) Inequality and happiness: are Europeans and Americans different? J Public Econ 88(9-10):2009-42

Allport GW (1954) The nature of prejudice. Addison-Wesley, Cambridge

Autor D, Dorn D, Hanson G, Majlesi K (2020) Importing political polarization? The electoral consequences of rising trade exposure. Am Econ Rev 110(10):3139-83

Bajo-Rubio O, Yan H-D (2019) Globalization and populism. In: Kwan DS, Yu F-LT (eds) Contemporary issues in international political economy. Palgrave Macmillan, Singapore, pp 229-52

Berggren N, Nilsson T (2015) Globalization and the transmission of social values: the case of tolerance. J Comp Econ 43(2):371-89

Bjørnskov C, Dreher A, Fischer JAV (2008) Cross-country determinants of life satisfaction: exploring different determinants across groups in society. Soc Choice Welf 30(1):119-73

Bjørnskov C, Dreher A, Fischer JAV, Schnellenbach J, Gehring K (2013) Inequality and happiness: when perceived social mobility and economic reality do not match. J Econ Behav Organ 91(1):75-92

Bluth C (2016) Attitudes to global trade and TTIP in Germany and the United States. Bertelsmann Stiftung, Gütersloh

Bown CP, Kolb M (2021) Trump's trade war time line: an up-to-date guide. Peterson Institute for International Economics, Washington DC. https://www.piie.com/sites/default/files/documents/trump-tradewar-timeline.pdf. Accessed 20 Oct 2021

Bremmer I (2018) Us vs. them: the failure of globalism. Portfolio/Penguin, New York

Buis ML (2010) Stata tip 87: interpretation of interactions in nonlinear models. Stata J 10(2):305-08

Case A, Deaton A (2015) Rising morbidity and mortality in midlife among white non-hispanic americans in the 21st century. Proc Natl Acad Sci 112(49):15078-83

Caselli M, Fracasso A, Traverso S (2020) Globalization and electoral outcomes: evidence from Italy. Econ Polit 32:68-103

Che Y, Lu Y, Pierce JR, Schott PK, Tao Z (2016) Does trade liberalization with China influence U.S. elections? In: NBER working paper no. 22178

Clark AE, Frijters P, Shields M (2008) Relative income, happiness and utility: an explanation for the Easterlin paradox and other puzzles. J Econ Lit 46:95-144

Colantone I, Stanig P (2018) The trade origins of economic nationalism: import competition and voting behavior in Western Europe. Am J Polit Sci 62(4):936-53

Colantone I, Stanig P (2018) Global competition and Brexit. Am Polit Sci Rev 112(2):201-18

Colantone I, Crinò R, Ogliari L (2019) Globalization and mental distress. J Int Econ 119:181-207

Di Tella R, MacCulloch RJ, Oswald AJ (2001) Preferences over inflation and unemployment: evidence from surveys of happiness. Am Econ Rev 91:335-341

Diener E (1984) Subjective well-being. Psychol Bull 95(3):542-75

Diener E, Inglehart R, Tay L (2013) Theory and validity of life satisfaction scales. Soc Indic Res 112(3):497-527

Dippel C, Gold R, Heblich S (2015) Globalization and its (dis-)content: trade shocks and voting behavior. In: NBER working paper no. 21812

Dluhosch B, Horgos D (2013) Trading up the happiness ladder. Soc Indic Res 113(3):973-90

Dluhosch B, Horgos D, Zimmermann KW (2014) Social choice and social unemployment-in-come cleavages: new insights from happiness research. J Happiness Stud 15:1513-37 
Dreher A (2006) Does globalization affect growth? Evidence from a new index of globalization. Appl Econ 38(10): 1091-110

European Values Study 2017: integrated dataset (EVS 2017). GESIS Data Archive, Cologne. ZA7500 Data file Version 3.0.0. https://doi.org/10.4232/1.13511

Evenett SJ, Fritz J (2021) The 27th global trade alert report. CEPR Press, London

Fattore C, Fitzpatrick B (2016) Perceived inequality and support for trade liberalization in Latin America. J Int Trade Law Policy 15(2/3):102-14

Feigenbaum JJ, Hall AB (2015) How legislators respond to localized economic shocks: evidence from Chinese import competition. J Polit 77(4):1012-30

Feng Y, Kerner A, Sumner JL (2021) Quitting globalization: trade-related job losses, nationalism, and resistance to FDI in the United States. Polit Sci Res Methods 9:292-311

Flynn DJ, Nyhan B, Reifler J (2017) Nature and origins of misperceptions: understanding false and unsupported beliefs about politics. Polit Psychol 38(S1):127-50

García-Muñoz TM, Milgram-Baleix J, Odeh-Odeh O (2019) Inequality and life satisfaction in lowand middle-income countries: the role of opportunity. Societies 9(2). https://doi.org/10.3390/ soc 9020037

Garrett RK, Weeks BE, Neo RL (2016) Driving a wedge between evidence and beliefs: how online ideological news exposure promotes political misperceptions. J Comput Mediat Commun 21(5):331-48

Gozgor G (2021) Global evidence on the determinants of public trust in government during COVID19. Appl Res Qual Life. https://doi.org/10.1007/s11482-020-09902-6

Gozgor G, Ranjan P (2017) Globalisation, inequality and redistribution: theory and evidence. World Econ 40:2704-51

Graham C, Felton A (2006) Inequality and happiness: insights from Latin America. J Econ Inequal 4(1):107-22

Graham C, Pinto S (2019) Unequal hopes and lives in the USA: optimism, race, place, and premature mortality. J Popul Econ 32:665-733

Guiso L, Herrera H, Morelli M, Sonno T (2017) Demand and supply of populism. In: CEPR discussion paper no. 11871

Gygli S, Haelg F, Potrafke N, Sturm J-E (2019) The KOF globalisation index-revisited. Rev Int Organ 14:543-74

Haerpfer C, Inglehart R, Moreno A, Welzel C, Kizilova K, Diez-Medrano J, Lagos M, Norris P, Ponarin E, Puranen B et al. (eds.) (2021) World values survey: round seven: country-pooled datafile, Madrid, Spain and Vienna: JD Systems Institute and WVSA Secretariat. http://www.worldvalue ssurvey.org/WVSDocumentationWV7.jsp. Accessed 24 Mar 2021

Hainmueller J, Hiscox MJ (2006) Learning to love globalization: education and individual attitudes toward international trade. Int Organ 60(2):469-98

Hanson GH, Scheve KF, Slaughter MJ (2007) Public finance and individual preferences over globalization strategies. Econ Polit 19(1):1-33

Helliwell JF, Wang S (2011) Trust and wellbeing. Int J Wellbeing 1(1):42-78

Hessami Z (2010) The size and composition of government spending in Europe and its impact on well-being. Kyklos 63(3):346-82

Hoekman B, Nelson DR (2018) Reflecting on populism and the economics of globalization. J Int Bus Policy 1(1-2):34-43

Hopkins E (2008) Inequality, happiness and relative concerns: what actually is their relationship? J Econ Inequal 6(4):351-72

Hummels D, Munch JR, Xiang C (2016) No pain, no gain: the effects of exports on effort, injury, and illness. In: NBER working paper no. 22365

Inglehart RF, Norris P (2016) Trump, Brexit, and the rise of populism: economic have-nots and cultural backlash. In: HKS Faculty Research working paper 16-026

Jensen JB, Quinn DP, Weymouth S (2017) Winners and losers in international trade: the effects on U.S. presidential voting. Int Organ 71(3):423-57

Jordahl H (2009) Economic inequality. In: Svendsen GT, Svendsen GLH (eds) Handbook of social capital: the troika of sociology, political science and economics. Edward Elgar, Cheltenham, pp $323-36$

Karaca-Mandic P, Norton EC, Dowd B (2012) Interaction terms in nonlinear models. Health Serv Res 47(1 Part I):255-74 
Khun C, Lahiri S, Lim S (2015) Do people really support trade restrictions? Cross-country evidence. J Int Trade Econ Dev 24(1):132-46

Leitner S, Gula B, Jannach D, Krieg-Holz U, Wall F (2021) Understanding the dynamics emerging from infodemics: a call to action for interdisciplinary research. SN Bus Econ 1(1):23

Lewis M (2018) The embedded liberalism compromise in the making of the GATT and Uruguay Round Agreements. In: Moon G, Toohey L (eds) The future of international economic integration: the embedded liberalism compromise revisited. Cambridge University Press, Cambridge, pp $12-30$

Lindner A (2005) International indicators of trade and economic linkages. OECD Room Document 13

Lü X, Scheve K, Slaughter MJ (2012) Inequity aversion and the international distribution of trade protection. Am J Polit Sci 56(3):638-54

Luttmer EFP (2005) Neighbors as negatives: relative earnings and well-being. Q J Econ 120:963-1002

Luxembourg Income Study (LIS) Database (2021) Available via http://www.lisdatacenter.org

Mansfield ED, Mutz DC (2013) Us versus them: mass attitudes toward offshore outsourcing. World Polit 65(4):571-608

Mayda AM, Rodrik D (2005) Why are some people (and countries) more protectionist than others? Eur Econ Rev 49(6):1393-430

Mutz DC (2018) Status threat, not economic hardship, explains the 2016 presidential vote. Proc Natl Acad Sci. https://doi.org/10.1073/pnas.1718155115

Mutz DC, Kim E (2017) The impact of in-group favoritism on trade preferences. Int Organ 71(4):827-50

Ngamaba KH, Panagioti M, Armitage CJ (2018) Income inequality and subjective well-being: a systematic review and meta-analysis. Qual Life Res 27(3):577-96

Nguyen Q (2017) Mind the gap? Rising income inequality and individual trade policy preferences. Eur J Polit Econ 50:92-105

Norton EC, Dowd BE (2018) Log odds and the interpretation of logit models. Health Serv Res 53(2):859-78

Norton EC, Wang H, Ai C (2004) Computing interaction effects and standard errors in logit and probit models. Stata J 4(2):154-67

Pavcnik N (2011) Globalization and within-country income inequality. In: Bacchetta M, Jansen M (eds) Making globalization socially sustainable. ILO/WTO publications, Geneva, pp 233-59

Pew Research Center (2014) Faith and skepticism about trade, foreign investment. Pew Research Center, Washington

Pierce JR, Schott PK (2020) Trade liberalization and mortality: evidence from US counties. Am Econ Rev Insights 2(1):47-64

Potrafke N (2015) The evidence on globalisation. World Econ 38(3):509-52

Putzhammer F (2018) Globalization, trade and populism in Germany. Analyzing the effects of trade exposure on voting behavior in the 2013 and 2017 German federal elections. Bertelsmann Stiftung, Gütersloh

Rodrik D (1998) Why do more open economies have bigger governments? J Polit Econ 106(5):997-1032

Rodrik D (2018) Populism and the economics of globalization. J Int Bus Policy 1:12-33

Rönkkö M, McIntosh CN, Antonakis J, Edwards JR (2016) Partial least squares path modeling: time for some serious second thoughts. J Oper Manag 47-48:9-27

Rözer J, Kraaykamp G (2013) Income inequality and subjective well-being: a cross-national study on the conditional effects of individual and national characteristics. Soc Indic Res 113(3):1009-23

Schalembier B (2016) The impact of exposure to other countries on life satisfaction: an international application of the relative income hypothesis. Soc Indic Res 128(1):221-39

Scheve KF, Slaughter MJ (2001) What determines individual trade-policy preferences? J Int Econ 54(2):267-92

Schneider SM (2016) Income inequality and subjective wellbeing: trends, challenges, and research directions. J Happiness Stud 17(4):1719-39

Schyns P (2002) Wealth of nations, individual income and life satisfaction in 42 countries: a multilevel approach. Soc Indic Res 60:5-40

Starmans C, Sheskin M, Bloom P (2017) Why people prefer unequal societies. Nat Hum Behav 1:0082

Tsoukis C (2007) Keeping up with the Joneses, growth, and distribution. Scot J Polit Econ 54(4):575-600 
Van Praag B (2011) Well-being inequality and reference groups: an agenda for new research. J Econ Inequal 9:111-27

VanderWeele TJ, Knol M (2014) A tutorial on interaction. Epidemiol Method 3(1):33-72

Walter S (2021) The backlash against globalization. Annu Rev Polit Sci 24:421-42

Williams R (2012) Using the margins command to estimate and interpret adjusted predictions and marginal effects. Stata J 12(2):308-31

Wold H (1982) Soft modeling: the basic design and some extensions. In: Jöreskog KG, Wold H (eds) Systems under indirect observation: causality, structure, prediction, vol 2. North-Holland, Amsterdam, pp $1-54$

Wood A (2018) The 1990s trade and wages debate in retrospect. World Econ 41:975-99

World Trade Organization (2019) Trade policy review of the United States presented by the WTO Secretariat, revised version. WTO, Geneva 